\title{
POSSIBILIDADES NA FORMAÇÃO DE CONCEITOS POR CRIANÇAS COM SÍNDROME DE DOWN NA ESCOLA COMUM
}

\author{
POSIBILIDADES EN LA FORMACIÓN DE CONCEPTOS POR NIÑOS CON \\ SÍNDROME DE DOWN EN LA ESCUELA
}

\section{POSSIBILITIES IN THE FORMATION OF CONCEPTS BY CHILDREN WITH DOWN SYNDROME AT THE COMMON SCHOOL}

\author{
Susana Couto Pimentel ${ }^{1}$ \\ https://orcid.org/0000-0002-6047-3198
}

\begin{abstract}
Resumo
Esta pesquisa, realizada com apoio da FAPESB, objetivou analisar o processo de apropriação de conceitos por estudante com Síndrome de Down (SD) inserida no segundo ano do Ensino Fundamental de uma escola comum. A metodologia utilizada foi a análise microgenética dos momentos de trabalho docente com conceitos na área de Ciências. A análise microgenética direciona o olhar do observador para o processo de internalização que ocorre a partir da mediação social. Os resultados apontam para a importância de mediações pedagógicas que favoreçam situações vivenciais, apoiadas nos conceitos cotidianos, para apropriação dos conceitos científicos, bem como para elaboração de estratégias de memorização. Conclui-se que o professor deve proporcionar atividades que favoreçam o avanço da criança com SD na internalização do pensamento conceitual, de modo a organizar suas percepções iniciais, vagas e sincréticas, em modos mais ordenados do pensamento que dão significado à experiência concreta.
\end{abstract}

Palavras-chave: Formação de conceitos. Síndrome de Down. Mediação.

\section{Resumen}

Esta investigación, realizada con el apoyo de la FAPESB, tuvo como objetivo analizar el proceso de apropiación de conceptos por parte de un estudiante con síndrome de Down (SD) insertado en el segundo año de la escuela primaria común. La metodología utilizada fue el análisis microgenético de los momentos de trabajo docente con conceptos en el área de las Ciencias. El análisis microgenético dirige la mirada del observador hacia el proceso de internalización que ocurre a partir de la mediación social. Los resultados apuntan para importancia de las mediaciones

\footnotetext{
${ }^{1}$ Doutora em Educação pela Universidade Federal da Bahia (UFBA). Professora associada da Universidade Federal do Recôncavo da Bahia (UFRB) onde ministra aulas na graduação e na pós-graduação no Programa de Pós-Graduação em Educação Científica, Inclusão e Diversidade (PPGECID - Mestrado Profissional) e no Programa de Pós-Graduação em Gestão de Políticas Públicas e Segurança Social (MPGPPSS - Mestrado Profissional).E-mail: scpimentel@ufrb.edu.br
}

\section{Como referenciar este artigo:}

PIMENTEL, S. C. Possibilidades na formação de conceitos por crianças com Síndrome de Down na escola comum. Revista Pedagógica, v. 23, p. 1-16, 2021 
pedagógicas que proporcionen situaciones prácticas, apoyadas por conceptos cotidianos, para la apropiación de conceptos científicos, así como para la elaboración de estrategias para memorizarlos. Se concluye que el maestro debe proporcionar actividades que favorezcan el avance del niño con SD para la internalización del pensamiento conceptual, con el fin de organizar sus percepciones iniciales, vagas y sincréticas, en formas de pensamiento más ordenadas que den sentido a la experiencia concreta.

Palabras clave: formación de conceptos. Sindrome de Down. Mediación.

\begin{abstract}
This research, carried out with the support of FAPESB, aimed to analyze the process of appropriation of concepts by a student with Down Syndrome (DS) inserted in the second year of elementary school in a common school. The methodology used was the microgenetic analysis of the moments of teaching work with concepts in the area of Sciences. Microgenetic analysis directs the observer's gaze to the internalization process that occurs from social mediation. The results point to the importance of pedagogical mediations that favor living situations, supported by daily concepts, for the appropriation of scientific concepts, as well as for the elaboration of strategies for memorizing them. It is concluded that the teacher should provide activities that favor the advancement of the child with DS in the internalization of conceptual thinking, in order to organize his initial, vague and syncretic perceptions, in more ordered ways of thinking that give meaning to the concrete experience.
\end{abstract}

Keyword: Formation of concepts - Syndrome of Down - mediation.

\title{
INTRODUÇÃO
}

A formação do pensamento conceitual está fortemente relacionada a categorizações, classificações e, consequentemente, ao desenvolvimento da linguagem, sendo este um processo ontogenético que acontece a partir da interação do indivíduo em contextos e atividades sociais específicas. Dentre esses contextos destaca-se a escola como locus cultural extremamente importante para favorecer a aquisição e a internalização de conceitos, devendo, nesse sentido, propiciar um ambiente que desafie a aprendizagem dos alunos e seu desenvolvimento.

Para a criança com Síndrome de Down (SD) esse processo de interação social é imprescindível. A SD, também chamada de trissomia do cromossomo 21, caracteriza-se por algumas peculiaridades dentre as quais um atraso ou limitação no desenvolvimento intelectual. Porém, embora as crianças com SD possuam alterações fenotípicas semelhantes, diferem entre si em aspectos gerais do desenvolvimento como linguagem, motricidade, socialização e habilidades da vida diária. Esta diferenciação está relacionada à 
maior ou menor incidência de interação com o contexto sociocultural e educacional do qual fazem parte.

Diante do reconhecimento da importância desses contextos de interação, optou-se nesta investigação pelo estudo e análise do processo de formação do pensamento conceitual no contexto escolar a partir do trabalho de mediação pedagógica. O objetivo pretendido foi analisar o processo de apropriação de conceitos por uma estudante com SD inserida em classe comum, a partir da ação mediadora do professor.

No percurso metodológico desta pesquisa buscou-se fazer a análise microgenética dos momentos de mediação pedagógica junto a estudante com SD, no trabalho com conceitos da área de Ciências. A análise microgenética é uma metodologia de pesquisa ancorada na matriz histórico-cultural e busca investigar "como acontecem" determinados processos humanos. Esta análise centra-se na gênese social de tais processos, isto é, nas transformações efetivadas a partir das relações entre sujeitos; nas mediações feitas e nas respostas dos sujeitos às mesmas (do plano intersubjetivo para o intrassubjetivo). De acordo com Vygotsky (2004), a análise microgenética direciona o olhar do observador para o processo de internalização que ocorre a partir da mediação social. Assim, a análise microgenética, enquanto método de investigação, propõe-se a desvendar os novos processos de aprendizagem e desenvolvimento originados a partir da interação social.

Nesta investigação, a análise microgenética foi realizada a partir da observação participante de momentos específicos de mediação pedagógica para acompanhar o processo de formação do pensamento conceitual. O trabalho investigativo foi realizado numa escola da rede particular de ensino do município de Feira de Santana - Bahia que, dentre outros, atendia a uma criança com SD que possuía nove anos de idade e cursava o segundo ano do Ensino Fundamental.

As atividades vivenciadas em sala de aula não foram apenas descritas, mas analisadas sob o ponto de vista da apropriação conceitual da criança com SD, de modo a apontar suas potencialidades no processo de formação de conceitos em contexto escolar de educação inclusiva. Para discorrer sobre essa temática, este texto está organizado em seções que abordam sobre o atendimento educacional às pessoas com SD; tratam questões relativas ao processo de formação do pensamento conceitual e, por fim, analisam os dados levantados durante a investigação. 


\section{ATENDIMENTO EDUCACIONAL ÀS PESSOAS COM SÍNDROME DE DOWN}

Historicamente as pessoas com SD eram tratadas a partir de uma visão que focalizava suas limitações e, portanto, eram educadas em ambientes educacionais especiais, segregadas da convivência com os demais aprendentes. O paradigma segregacionista, que dava suporte a tais práticas, preconizava um sistema educacional dividido em dois subsistemas: regular e especial.

Posteriormente, o atendimento às necessidades educacionais especiais passou a ser baseado na proposta da "normalização" da pessoa com deficiência com o objetivo de torná-la apta para atender aos padrões estabelecidos socialmente, sendo regido pelo paradigma educacional da integração escolar. Essa concepção parte do pressuposto que a escola trabalha da forma correta e, portanto, os alunos precisam submeter-se a ela. "Em suma, a escola não muda como um todo, mas os alunos têm de mudar para se adaptarem às suas exigências" (MANTOAN, 2003, p. 23).

Embora esta visão ainda não tenha sido totalmente superada, as discussões na década de 1990 iniciadas no cenário internacional, a respeito do processo de educação para todos, trouxeram para o Brasil o desafio de construir sistemas de ensino capazes de atender às novas demandas presentes na escola.

Nessa perspectiva, é importante ressaltar que o atendimento às necessidades dos educandos implica em interações e trocas com o meio sócio-cultural-educacional. Porém, tais trocas estão fortemente relacionadas com a forma como a sociedade lida com a diferença. Entretanto, as vivências escolares têm mostrado que quanto mais visíveis são as diferenças mais estranhamento causam à sociedade.

No caso das pessoas com SD existem traços fenotípicos que as caracterizam. Isso contribui para a elaboração de estigmas a elas impostos pela sociedade. Para Goffman (1988), o estigma é uma identidade social produzida a partir de referências depreciativas que não correspondem às exigências sociais do que o indivíduo deveria ser. Este estigma constitui-se num estereótipo, criado socialmente, que reduz a pessoa ao seu "defeito" ou a sua "desvantagem". Portanto, no caso das pessoas com SD, a visibilidade de sua diferença constitui-se num desafio a mais a ser vencido no processo de interação com vistas a desconstrução de preconceitos. 
Ademais, o estigma imputado à pessoa com SD não se reduz ao que é visível em suas características físicas, mas envolve o quadro de deficiência intelectual associado. Esta situação de desvantagem cognitiva traz consigo o estigma da inferioridade, da incapacidade que contribui para a discriminação. Tais preconceitos são construídos sob um padrão de julgamento elaborado socialmente a partir de um conjunto de expectativas normativas. Assim, quando o indivíduo com SD não consegue corresponder ao que lhe foi efetivamente exigido, ele é estigmatizado.

No entanto, o paradigma da inclusão educacional prevê o atendimento às necessidades dos educandos que se inserem na escola regular, o que significa passar a ouvir e ver aqueles sobre quem não se falava, ouvia e via. Passar a ouvi-los e vê-los significa estar disposto a buscar pistas e indícios que apontem a melhor forma de ajudá-los a aprender. Para isso, é necessário valorizar as referências individuais, prestar atenção às singularidades e, a partir daí, estabelecer mediações pedagógicas que favoreçam aprendizagens.

Nesse sentido, torna-se necessário romper com o currículo homogeneizador que não considera singularidades, fazendo-se necessário avançar em direção a um currículo que permita o encontro com a diferença e o acolhimento ao diferente, proporcionando a interação e a aprendizagem mediada, colaborativa e compartilhada.

No caso dos discentes com SD, por exemplo, é importante considerar que suas “conexões cerebrais [...] são mais lentas e fracas e por isso requerem mais repetições. A integração entre a ordem verbal e a resposta é difícil, porque a criança precisa fazer uma síntese entre a fala, a instrução e a ação" (MILANI, 2005, p. 50). Nesse sentido, a comunidade escolar que interage com essa criança precisa criar possibilidades de envolvêla no processo de aprendizagem, considerando o seu tempo necessário para formação do conceito. Na tentativa de compreender a elaboração de conceitos pela pessoa com SD é necessário inicialmente que se discuta o processo de formação do pensamento conceitual.

\section{O PROCESSO DE FORMAÇÃO DO PENSAMENTO CONCEITUAL}

A discussão trazida por Vygotsky (2001) sobre formação de conceitos enfoca, essencialmente, o desenvolvimento do pensamento vinculado ao processo de 
aprendizagem. "Na perspectiva vigotskiana, os conceitos são entendidos como um sistema de relações e generalizações contido nas palavras e determinado por um processo histórico-cultural" (REGO, 2001, p.76).

Como se trata de um fenômeno sócio-histórico-cultural, o significado das palavras não é imutável, mas evolui da mesma forma que, na ontogênese, a natureza psicológica humana também muda, pois parte de generalizações mais primitivas ou concretas e elevase ao nível dos conceitos mais abstratos. Cada palavra aprendida pela criança representa uma generalização, inicialmente do tipo mais primitivo, para em seguida ser substituída por generalizações mais complexas chegando à formação dos conceitos verdadeiros. Assim, Vygotsky (1993) considera a formação de conceitos como uma função que compõe o crescimento social e cultural da pessoa e que afeta o conteúdo e o método do seu raciocínio. "A formação dos conceitos é seguida por sua transferência para outros objetos: o sujeito é induzido a utilizar os novos termos ao falar sobre outros objetos [...], e a definir o seu significado de uma forma generalizada”. (VYGOTSKY, 1993, p. 49).

Em suas pesquisas, Vygotsky (1993) demonstra que na trajetória até a formação de conceitos há três fases. Na primeira fase há uma agregação desorganizada ou sincrética de objetos isolados. Isto é, a criança mistura diferentes elementos do objeto de forma desarticulada, agrupando objetos desiguais, sob o significado de uma palavra, com nexos vagos e relações difusas vinculadas a uma imagem mutável em sua mente.

A segunda fase é chamada de pensamento por complexos e nela as associações, feitas pela criança, partem de relações existentes entre os objetos. Nessa fase, há um avanço em direção ao pensamento objetivo e coerente, além de uma busca por formar agrupamentos de objetos como famílias mutuamente relacionadas. Entretanto, as relações feitas são concretas e factuais, realizadas com base na experiência direta da criança, e não baseadas numa lógica abstrata.

A terceira fase, descrita por Vygotsky, é denominada de conceitos potenciais que são resultados de uma abstração primitiva, com formação de agrupamentos com base em um único atributo. Esta abstração pode ser formada a partir do pensamento perceptual baseado em impressões semelhantes, ou também a partir da ação ou do pensamento prático com base em significados funcionais semelhantes. Um exemplo de formação do conceito potencial é quando a criança consegue, a partir de uma palavra dada, dizer o que 
o seu objeto referente pode fazer ou o que pode ser feito com ele, embora não consiga definir verbal e abstratamente tal conceito.

Por se tratar de um ato complexo do pensamento, Vygotsky considera que a transmissão ou o ensino direto de conceitos é infrutífero.

\footnotetext{
Um professor que tenta fazer isso geralmente não obtém qualquer resultado, exceto o verbalismo vazio, uma repetição de palavras pela criança, semelhante a um papagaio, que simula um conhecimento dos conceitos correspondentes, mas que na realidade oculta um vácuo (VIGOTSKI, 1993, p.72).
}

Embora entendendo a impossibilidade da transmissão de conceitos do professor para o educando, a linguagem desenvolvida, a partir das interações com seu entorno, possibilitará à criança mais possibilidade de generalizações, o que é um poderoso fator no desenvolvimento do pensamento conceitual. Assim, Vygotsky aponta o aprendizado como uma das principais fontes de conceitos da criança em idade escolar, devendo ser construído em função do desenvolvimento do pensamento da criança.

Nesse sentido, os professores devem atuar na zona de desenvolvimento proximal (ZDP) dos seus alunos, isto é, investir naquilo que ainda não está dado, mas está potencialmente capaz de se desenvolver, buscando maximizar a eficiência do ensino. Para Vygotsky (1998, p. 112), a ZDP é determinada "através da solução de problemas sob a orientação de um adulto ou em colaboração com companheiros mais capazes".

Desse modo, o conceito de ZDP é considerado um dos mais produtivos da teoria vigotskiana, pois fornece base para reestruturação do processo de ensino de modo que este promova o desenvolvimento. "[...] é necessário que o ensino se apoie não apenas no já alcançado pela criança, mas nos processos que se desenvolvem e nos que ainda estão em formação". (VIGOTSKI, 1995, p. 300). Isso torna o conceito de ZDP estratégico para a educação inclusiva, pois “demonstra o caráter dialético do processo de desenvolvimento [... ] e contribui para o estudo e o ensino de crianças anormais e para análise da efetividade do processo pedagógico" (VIGOTSKI, 1995, p. 300).

Compreendendo o papel do outro social no processo de formação do pensamento conceitual, Vygotsky discorre em seus estudos sobre dois tipos de conceitos: os cotidianos ou espontâneos e os científicos. Os chamados conceitos cotidianos são formados a partir das propriedades perceptivas, funcionais ou contextuais daquilo a que refere; partem de 
vivências, da observação do mundo, dos questionamentos dirigidos às pessoas mais experientes, podendo alcançar um nível de abstração; são "generalização de coisas". Nessa aprendizagem cotidiana o objeto é experienciado, mas não há preocupação com sua apreensão verbal.

Por sua vez, os conceitos científicos são "generalização de pensamentos" e permitem refletir sobre o que não está ao alcance dos conceitos cotidianos, a essência do objeto. Assim, a formação do conceito científico é inicialmente mediada por outro conceito (cotidiano) que fornece base para a sua internalização, ou seja, para compreensão das construções culturais sistematizadas ao longo da história da humanidade. Portanto, a formação dos conceitos científicos é oposta à dos conceitos cotidianos. Se esses partem do concreto para o abstrato, àqueles partem do abstrato ao concreto (LEONTIEV, 1988).

Desse modo, quando a criança chega na escola os conceitos cotidianos já construídos apontam para o seu desenvolvimento real, ou seja, aquilo que ela já internalizou como resultado da interação com outros em sua vivência e que, portanto, já pode dar conta sozinha. Já os conceitos científicos ainda apontam, no momento inicial da escolarização, para a ZDP da criança, isto é, aquilo que ela pode conseguir com ajuda de outra pessoa mais experiente. É importante lembrar que essa ajuda não deve estar associada à ideia de dependência, ao contrário, a proposta vigotskiana de mediação na zona de desenvolvimento proximal é permeada pela concepção de internalização, ou seja, aquilo que hoje a criança precisa de ajuda para fazer, poderá fazer sozinha amanhã.

Com relação à criança com SD é preciso reafirmar que, da mesma forma que as demais as crianças, o seu desenvolvimento se dá a partir da interação com outros membros do seu entorno cultural. Embora o desenvolvimento da linguagem nessas crianças aconteça num tempo diferenciado em virtude da hipotonia dos órgãos fonoarticulatórios e do seu tempo de desenvolvimento cognitivo, as interações sociais e as mediações do seu interlocutor, o mais precocemente possível, trarão a possibilidade de apropriação de novos conteúdos significativos para o seu crescimento.

Diante disso, o interlocutor com o qual a criança com SD interage, também precisará ficar atento para outras formas de manifestação da linguagem utilizadas pela criança (oral, gestual, gráfica etc.), pois, a depender do momento de seu desenvolvimento, a criança poderá fazer uso de diferentes formas de comunicação para propiciar o fluxo de trocas de 
significados durante as interações. Os usos dessas formas alternativas de comunicação podem também contribuir para ampliar o vocabulário total dessas crianças e, paralelamente, contribuir para a aquisição de conceitos.

Compreendendo a importância dessas interações sociais no processo de aprendizagem e desenvolvimento de crianças com SD, esta investigação pretendeu registrar como as crianças com SD constroem os conceitos trabalhados pela escola, a partir do processo de mediação pedagógica.

\section{DESENVOLVIMENTO OS RESULTADOS DA PESQUISA}

Com vistas a compreender a formação de conceitos por criança com SD na escola regular, esta investigação foi realizada na área de Ciências Naturais sendo observado, durante três unidades letivas, o trabalho com os seguintes conteúdos: recursos naturais: água, ar e solo; corpo humano e alimentação; animais. Os avanços na apropriação de conceitos por Lily, nome fictício da criança com SD, foram observados através da análise microgenética dos momentos de mediação pedagógica.

A classe onde Lily estava inserida apresentava um perfil muito participativo e de fácil aprendizagem. Dentre os discentes, havia na turma um aluno com treze anos - Robson que demonstrava dificuldades na aprendizagem e inadaptação a algumas regras escolares. Apesar disso, ele participava e se envolvia nas atividades proporcionadas pela professora. Havia na classe outra criança - Catarina, muito tímida, que falava com voz quase inaudível, mas demonstrava muitas habilidades artísticas, principalmente com desenho. As demais crianças gostavam de se expressar e de se posicionar em relação a todos os assuntos trazidos pela professora. Isso, talvez, dificultasse um maior envolvimento espontâneo de Catarina e de Lily. Porém, a professora sempre pedia a participação de todos e estimulava o grupo a ouvir e respeitar as diversas opiniões.

É importante enfatizar que para realização da pesquisa foram observados os princípios éticos de uma investigação envolvendo seres humanos. Além da anuência da escola e do assentimento dos estudantes, os pais foram informados dos objetivos da investigação e assinaram um termo de consentimento livre e esclarecido, autorizando a 
filmagem das aulas e o uso da mesma para fins de levantamento de dados. Com vistas a garantir o sigilo dos participantes, todos os nomes utilizados nas transcrições são fictícios.

Na situação transcrita a seguir a professora utiliza-se de softwares nas aulas de informática para, em seguida, trabalhar o conceito de esqueleto humano.

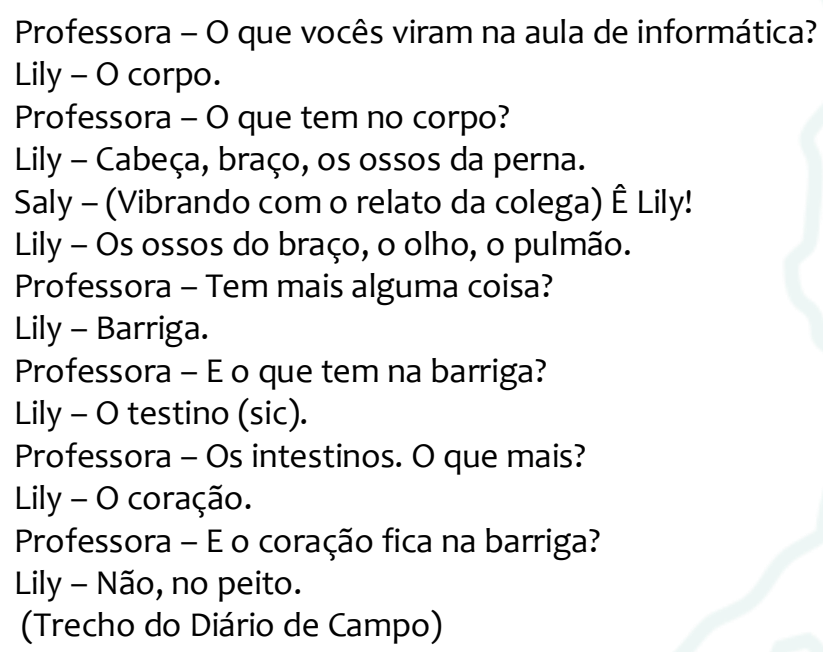

Como num pensamento por complexos, Lily acaba listando verbalmente alguns órgãos do corpo vistos na aula de informática, mas não demonstra apropriação do conceito de esqueleto humano, nem estabelece elos entre as palavras listadas. Porém, observa-se que os questionamentos feitos pela docente não possibilitaram a transposição dos vocábulos isolados para a formação de um conceito como rede semântica. Isso foi percebido também nas atividades escritas onde os conceitos foram trabalhados como significados dicionarizados, sem que se fizesse uma rede semântica entre os mesmos. Por exemplo: "O conjunto de órgãos do nosso corpo chama-se esqueleto" ou "O encontro de dois ossos é chamado articulação".

Para Reuven Feuerstein, "o desenvolvimento cognitivo e a manifestação da aprendizagem são efeitos de um tipo muito específico de interação humana por excelência" (GOMES, 2002, p. 73). Deste modo, para que haja mudança na estrutura cognitiva de uma pessoa com deficiência intelectual, é necessária "uma relação qualitativa de interação mediada com um outro ser humano já desenvolvido" (GOMES, 2002, p. 83). Neste caso, apesar da atividade pedagógica proposta ter possibilitado o envolvimento da criança com SD e a possibilidade de compartilhamento dos saberes aprendidos, faltou, na 


\section{REVISTA}

\section{Revista do Programa de Pós-Graduação em Educação da Unochapecó ISSN 1984-1566 (on-line) ISSN 1415-8175 (impressa)}

mediação da professora, uma intervenção eficaz que possibilitasse a construção de significados do conhecimento trabalhado.

Outra característica observada nas respostas de Lily era a predominância de um modo de pensar relacionado com a experiência, com a realidade concreta imediata, indicando uma forma de pensamento prático. Na aula transcrita a seguir os estudantes haviam trazido alguns alimentos.

Professora - Lily, você sabe por que é importante você se alimentar?

Lily - Sei. Paladar.

Professora - Você consegue se alimentar através do paladar... E por que é importante você comer tudo isso aqui (aponta alimentos levados pelas crianças)? Lily - (Abaixa a cabeça e começa a apontar e nomear os alimentos) Cenoura, batata, maçã... Hambúrguer...

Professora - (...) E você precisa desses alimentos Lily?

Lily - Precisa desses dois (mostra o macarrão e o pimentão que estão mais próximos dela).

Professora - E se você não comesse você poderia andar e estudar?

Lily - (Assustada). Não.

Professora - Ficava muito forte ou muito fraca?

Lily - Muito fraca.

Professora - Nós começamos primeiro falar sobre o corpo humano, aí nós vimos que ele passa por várias transformações, ele tem um processo de crescimento e pra tudo isso é necessário a alimentação. Então, a alimentação tem um papel importante.

(Trecho de transcrição de filmagem de aula).

Na transcrição acima observa-se também que Lily demonstra ter se apropriado de um conceito trabalhado em aulas anteriores, fazendo relação entre o paladar e a alimentação. Essas respostas que ora se aproximam de um pensamento conceitual mais elaborado e dinamicamente relacionado a outros conceitos, ora se distanciam dele recorrendo à experiência pessoal, indicam que o desenvolvimento do pensamento conceitual não é linear, ele avança e retrocede, pois não está preso a etapas que se sucedem.

Analisando a mediação pedagógica com base nos critérios do processo mediacional desenvolvido por Feuerstein (GOMES, 2002), observa-se que a docente criou uma situação de mediação que possibilitou, em parte, a transcendência da realidade concreta, ou seja, a aplicação de um conceito anteriormente aprendido (paladar) a um novo contexto (alimentação). Porém, ainda há novos conceitos a serem intencionalmente mediados de modo que possibilite à criança com SD a construção de novos significados. 
O nível da operação cognitiva da criança com Síndrome de Down é amplamente determinado por sua condição cromossômica; no entanto, a intervenção social e educacional pode transformar significativamente as restrições produzidas pelos cromossomas, como apontado por um jornalista do Le Monde: "O cromossoma não tem a última palavra”. (FEUERSTEIN apud GOMES, 2002, p. 15).

O trecho a seguir demonstra um momento de mediação no qual a professora buscava favorecer para Lily a percepção de agrupamentos, categorizações e classificação. Nessa aula, a professora solicita que, em duplas, os alunos elaborem um cartaz com o registro do que eles já sabem e do que querem saber sobre animais. Lily faz o trabalho junto com Beatriz.

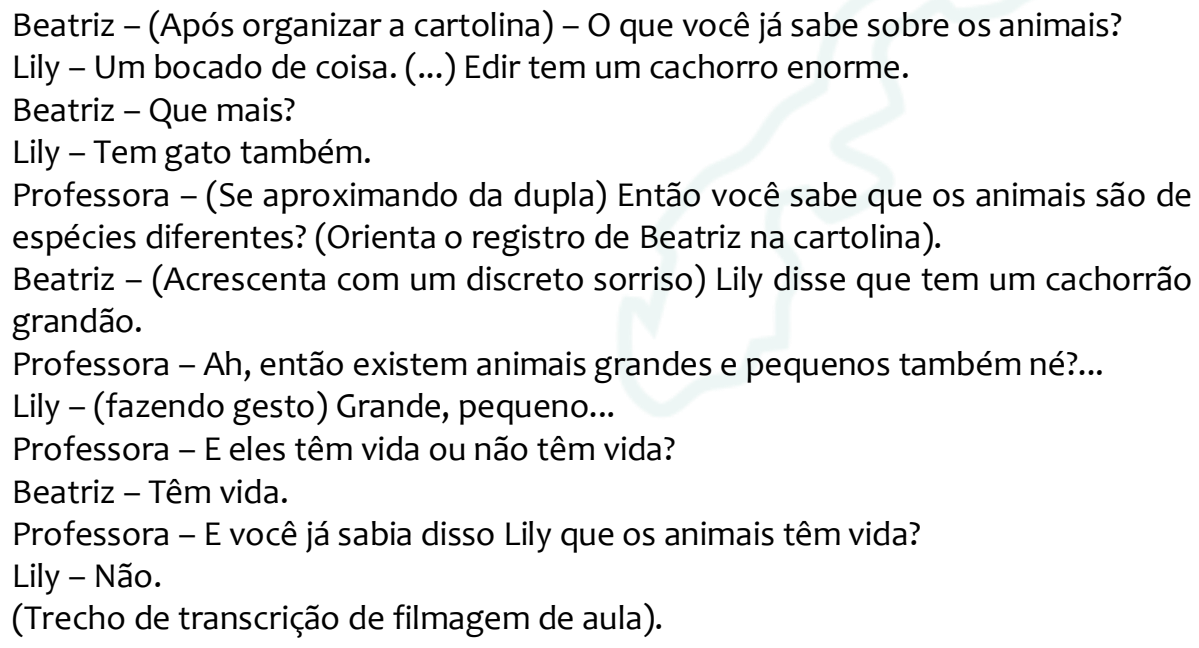

Observa-se que a professora sistematiza as falas de Lily que se apresentam com predominância do pensamento prático e com dificuldade de abstrair da experiência. A professora exerce o importante papel mediador de estabelecer categorias para organizar o seu pensamento. Analisando essa mediação com base nos critérios estabelecidos por Feuerstein (GOMES, 2002), nota-se uma mediação intencional de significado, onde a professora fornece significados para que a criança com SD possa elaborar novos significados e possibilidades na formação do pensamento conceitual.

No trecho a seguir, a professora busca interagir com Lily a fim de criar ZDP e assim proporcionar a internalização dos conceitos trabalhados. As respostas de Lily estimulavam a formulação de outras questões, pela professora, visando a produção de outras respostas, 
REVISTA

Revista do Programa de Pós-Graduação em Educação da Unochapecó

ISSN 1984-1566 (on-line) ISSN 1415-8175 (impressa)

de modo a dar visibilidade ao seu modo próprio de pensar, buscando chamar sua atenção para aspectos essenciais e levá-la aos processos de classificação e generalização, necessários à formação do conceito. Observa-se, então, que há uma mediação intencional, de significado e de transcendência (GOMES, 2002), na qual a professora 'caminha' junto com a criança com SD, criando possibilidades para que ela possa extrapolar a aprendizagem dos conceitos, aplicando-os a novas situações em novos contextos.

Professora - (Mostrando gravuras de animais) Se nós fôssemos classificar esses animais em vertebrados e invertebrados, eles seriam o que?

Saly - Vertebrados.

Professora - E por que eles seriam vertebrados, você sabe Lily?

Lily - Acena negativamente com a cabeça.

Crianças - Eles têm ossos. (...)

Professora - O mico-leão seria o que?

Saly - Mamífero.

Professora - E a onça pintada Lily? (...)

Lily - Tem ossos, tem barriga, tem rabo, tem pernas e não voa. (...) Só faz andar.

Professora - E ele é um mamífero?

Lily - É mamífero.

Professora - E aqui a arara?

Lily - A arara azul fica nas árvores... E a arara azul é assim... É bonito.

Professora - Ela é igual à onça?

Lily - Não.

Professora - No lugar das patas ela tem o que?

Lily - Ela vua (sic).

Professora - Ela voa. Muito bem! Será que ela come carne Lily?

Lily - Não.

Professora - E a onça come?

Lily - Come. (...) Olhe aqui ó (Dirigindo-se a turma)... Aqui é o macaco leão dourado. Ele é assim... É um mamífero. Ele tem barriguinha, uma perna, tem um braço, tem pernas, tem ossos.

Professora - Tem ossos. Então, ele é o que? Verte...

Lily - Ral.

Professora - Ele mama?

Lily - Não!

(Trecho de transcrição de filmagem de aula).

Observa-se mais uma vez a oscilação do pensamento de Lily, isto é, a não linearidade em direção à formação do pensamento conceitual. É possível afirmar que nesse excerto há indícios de conceito potencial, pois Lily sinaliza com possibilidades reais de avançar na formação do pensamento conceitual abstrato. Por isso, Mortimer (2006, p. 367) sugere que o ensino de conceitos na área de Ciências resulte de um "diálogo entre os discursos científico e cotidiano, no qual novos significados são tanto construídos como transmitidos". Isso implica que a escola trabalhe o conhecimento científico não como uma 
univocidade com superioridade da voz científica, determinando os discursos do aprendente, mas reconhecendo que as aulas de Ciências devem ser constituídas como um espaço caracterizado por uma multiplicidade de vozes que refletem a existência de perfis conceituais diferentes, mas que se complementam.

\section{CONSIDERAÇÕES FINAIS}

Retomando o objetivo proposto neste estudo de analisar o processo de apropriação de conceitos por uma estudante com SD inserida em classe comum, a partir da ação mediadora do professor, foi possível constatar, a partir dos dados da pesquisa, que a mediação pedagógica é imprescindível para a formação de conceitos por estudantes com SD na escola comum e, consequentemente, para o sucesso da inclusão.

Essa ação mediadora docente deve se iniciar no planejamento de atividades, pois embora a formação de conceitos exija um nível de abstração e generalização, isto não impede que o professor parta de situações vivenciais/experienciais para possibilitar reflexões e estabelecimento de relações. Tais situações possibilitam, especificamente, o avanço da criança com SD na internalização do pensamento conceitual, de modo a organizar suas percepções iniciais vagas e sincréticas (conceitos cotidianos) em modos mais ordenados do pensamento (conceitos científicos) que dão significado à experiência concreta.

Outro aspecto a se destacar na ação mediadora observada é a relevância do trabalho em pequenos grupos, da ação conjunta com os pares, possibilitando para as crianças uma aprendizagem colaborativa. Essa ação colaborativa, além de favorecer a aprendizagem, potencializa também o processo de inclusão.

$\mathrm{Na}$ área específica de Ciências, a análise microgenética traz indícios de que, nas séries iniciais do ensino fundamental, o ensino de conceitos científicos favorece uma mudança no perfil conceitual prévio do estudante, com a inclusão de novas ideias científicas. Mas esses “novos” conceitos parecem passar a conviver com os anteriores sem, necessariamente, substituí-los.

Outra constatação foi que as fases apontadas por Vygotsky no processo de formação do pensamento conceitual não são lineares em sua construção, elas coexistem, 
avançando até a possibilidade de formação de conceitos verdadeiros. Isto indica um processo em desenvolvimento na formação do pensamento conceitual e, ainda que a verbalização consciente do conceito só aconteça na adolescência, a escola não deve se abster de trabalhá-lo desde o ensino fundamental, de modo a aproximar os estudantes de outras terminologias e novas formas de utilização dos conceitos.

Observou-se também nesta investigação que, na criança com SD observada, o pensamento por complexo é o que mais se apresenta no processo de formação de conceitos, porém ela confirma a possibilidade evolutiva, ontogenética e sociogenética, de alcançarem o pensamento conceitual abstrato, o que Vygotsky denomina de conceitos verdadeiros. Essa predominância do pensamento por complexos, indica tanto a fixação na função e no significado concreto e literal das palavras apresentadas, quanto a dificuldade, neste momento específico do desenvolvimento, de se efetuar a abstração e a busca do significado das palavras, típica de um comportamento abstrato. No entanto, isso é perfeitamente compatível com o momento de desenvolvimento da criança. Porém, embora se tenha essa compreensão, é necessário que o professor, mediador do processo de formação do pensamento conceitual, compreenda que, por sua própria natureza de rede semântica, os conceitos não devem ser trabalhados isoladamente, devendo constituir uma rede de significados relacionados e estruturados.

\section{REFERÊNCIAS}

GOFFMAN, E. Estigma: notas sobre a manipulação da identidade deteriorada. Rio de Janeiro - RJ: Livros Técnicos e Científicos Editora S.A., 1988.

GOMES, C.M.A. Feuerstein e a construção mediada do conhecimento. Porto Alegre: Artmed, 2002.

LEONTIEV, A.N. Uma contribuição à teoria do desenvolvimento da psique infantil. In: VIGOTSKII L.S.; LURIA, A.R.; LEONTIEV, A.N. Linguagem, desenvolvimento e aprendizagem. São Paulo: Ícone, 1988.

MANTOAN, M.T.E. Inclusão escolar: o que é? Por quê? Como fazer? São Paulo: Moderna, 2003.

MILANI, D. Down, Síndrome de: como - onde - quando - porque. São Paulo: Livro Pronto, 2005. 
MORTIMER, E. F. Linguagem e formação de conceitos no ensino de Ciências. 2. ed. Belo Horizonte: Ed. UFMG, 2006.

REGO, T.C. Vygotsky: uma perspectiva histórico-cultural da educação. 11. ed., Petrópolis, RJ: Vozes, 2001.

VYGOTSKY, L.S. Fundamentos de defectología. Obras Completas Tomo Cinco. Editora Pueblo y Educación: Ciudad de La Habana, 1995.

VYGOTSKY, L.S. A formação social da mente. 6. ed. São Paulo: Martins Fontes, 1998.

VYGOTSKY, L.S. Pensamento e linguagem. São Paulo: Martins Fontes, 1993.

VYGOTSKY, L.S. Psicologia Pedagógica. São Paulo: Martins Fontes, 2001.

VYGOTSKY, L.S. Teoria e método em Psicologia. 3. ed. São Paulo: Martins Fontes, 2004.

Enviado em: 01-10-2020

Aceito em: 20-11-2020

Publicado em: 07-01-2021 